\title{
Estimating local records for Northern and Central Italy from a sparse secular temperature network and from 1961-1990 climatologies
}

\author{
M. Brunetti ${ }^{1}$, G. Lentini ${ }^{2}$, M. Maugeri ${ }^{2}$, T. Nanni ${ }^{1}$, C. Simolo ${ }^{1}$, and J. Spinoni ${ }^{2}$ \\ ${ }^{1}$ Istituto per le Scienze dell' Atmosfera e del Clima, CNR, via Gobetti 101, 40129 Bologna, Italy \\ ${ }^{2}$ Dipartimento di Fisica, Università degli Studi di Milano, via Celoria 16, 20133 Milano, Italy
}

Received: 1 December 2008 - Revised: 7 April 2009 - Accepted: 16 April 2009 - Published: 29 April 2009

\begin{abstract}
The paper presents monthly 30 -arc-second-resolution Northern and Central Italy temperature climatologies and discusses the procedure we adopt to superimpose the information of temperature secular records onto these climatologies. The climatologies are obtained by means of a step-wise linear regression method which aims at determining the temperature dependence on geographical and morphological variables. Such a method is applied to a database of about 800 monthly 1961-1990 temperature normals. In the first regression (temperature vs. elevation) the recorded data are considered; the further regressions concern the residuals obtained after taking into account the effect of each variable, in order of importance. An estimated secular anomaly record can be obtained for each point of the climatology grid by means of a distance-weighted average of the temperature anomaly records of the stations surrounding the grid point.
\end{abstract}

\section{Introduction}

A ten-year research programme developed by the Institute of Atmospheric Sciences and Climate (ISAC-CNR) and the University of Milan enabled the setting up of a database of quality-checked and homogenised meteorological secular records covering the whole Italian territory (Brunetti et al., 2006).

Temperature series display a spatial distribution of about one station per $4000 \mathrm{~km}^{2}$. They were used both to obtain coarse resolution regional mean series and to construct a 1degree-resolution gridded version of the data (Brunetti et al., 2006). Both the regional and the gridded temperature series consist of monthly anomalies, expressed in terms of differences from the 1961-1990 normal values (Brunetti et al., 2006). The regional and the gridded series were not obtained starting from the absolute value records, because the records obtained by means of such data are highly vulnerable to fluctuations in spatial coverage. For example, if there is a gap in the record at a cold high-level station, then the regional average and the grid point series depending on it may be warm biased. This vulnerability is so important that, when absolute value temperatures are used, the calculation of the regional and the gridded series has to be restricted to the period of full data availability of all records (Mitchell and Jones, 2005). It is also important to underline that the missing data are not the only problem. In fact, especially over areas with a complex orography like Italy, absolute temperatures show a very high spatial variability, causing each station to be truly representative only of its exact location. So, it is improper to suppose that the small number of stations used by Brunetti et al. (2006) to calculate a grid point record (usually from 3 to 5) or a coarse resolution regional mean series (usually from 20 to 25) can actually be representative of the real average temperatures over the corresponding areas. Similar problems do not concern anomalies because their variations take place on a much larger spatial scale. Such a greater spatial coherence causes the anomalies to be much less vulnerable to missing data and much more suitable for the calculation of regional average or gridded series. The shortcoming of the anomaly series is that they contain less information than the corresponding absolute value series: such a problem can make them scarcely useful for the needs of researchers involved in climate change impact-related studies.

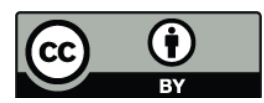

Correspondence to: M. Maugeri

(maurizio.maugeri@unimi.it) 
At the beginning of 2006 we set up a new research programme with the aim of developing a methodology allowing the estimation of secular absolute value temperature records for any point of Italy. The first step of this research involved Northern and Central Italy.

The basic assumption we adopt is that the spatio-temporal structure of the temperature signal over a given area can be described by the superimposition of two fields: the climate normals over a given reference period (i.e. the climatologies) and the departures from them (i.e. the anomalies) (New et al., 2000; Mitchell and Jones, 2005). The former are basically linked to the geographical features of the territory and they can manifest remarkable spatial gradients. On the contrary, the latter are linked to climate variability and change and they are generally characterised by higher spatial coherence. These two fields can be reconstructed in a completely independent way from each other and they can be based on completely different data.

The paper summarises the main results obtained so far. It is organised in five sections. After the introduction, Sect. 2 presents the database, considering both the records we used to construct the climatologies and the ones we used to describe the spatio-temporal behaviour of the temperature anomalies. Section 3 deals with the estimation of the most appropriate secular anomaly record for each point of the climatology grid. Section 4 focuses on the 1961-1990 temperature climatologies and shows the procedure we adopt to superimpose the climatologies and the temperature anomalies. In the end, Sect. 5 summarizes the results of the paper and discusses some open problems.

\section{Data}

The database we used to describe the spatio-temporal behaviour of the temperature anomalies is an updated version of the Italian quality checked and homogenised secular temperature database presented in Brunetti et al. (2006). It covers the whole Italian territory, encompassing 67 sites and including some of the longest and most studied records in the world, like Milan and Padua. In the near future such database will be subjected to new investigations to reconsider the homogenisation of the data recorded before 1865; moreover, new records will be included to enhance the spatial resolution. The inclusion of new records is however not an absolute priority because, due to the very high spatial coherence of the time-dependent component of air temperature, the 67 records of the database are sufficient to reasonably capture temperature variability and change over most areas of Italy (Brunetti et al., 2006); the only important exception is probably the high elevation Alpine areas in winter and autumn.

The spatial patterns of the 1961-1990 monthly temperature normals are based on a completely different database. In this case the main objective was to get as many data as possible. So, we first performed a detailed inventory of all North- ern and Central Italy digitalised record sources and selected the series with less than 50\% missing data in the 1961-1990 period. Then we also looked for the digitalised records with more than 15 years of data, even though they are not related to the 1961-1990 period, or cover it only partially. Then we also looked for non-digitalised records and considered a collection of national records that was published by the Italian Hydrological Service in the 1960s (Servizio Idrografico, 1966). Finally, we also considered monthly 1961-1990 normals from the ENEA climatological database (Petrarca et al., 1999), even though the monthly time series were not available to us. Besides the Italian data, we also considered a few non-Italian stations.

The total number of sites is 767 . This number includes only the stations that were considered after a quality check procedure, which consisted of checking all sites for their position (at least the consistency among position and elevation was verified) and deleting the ones that could not be correctly located. A further check concerned the stations which were included in more than one source: in this case only the most reliable version in terms of data availability was considered.

From each data series the 1961-1990 temperature monthly climatological normals were evaluated. When the 19611990 period was not completely available (or not available at all), the database used to describe the temperature anomalies was used to adjust the normals to the 1961-1990 period: the details are given in Sect. 3. The monthly normals were also used to further check the data: all station normals were compared with the ones of the neighbouring stations to delete the stations with the most evident errors.

A significant fraction (about $40 \%$ ) of the stations used in this study were already considered in the high resolution temperature climatologies obtained for the Greater Alpine Region within the ECSN HRT-GAR project (Auer et al., 2008; Hiebl et al., 2009). The ECSN HRT-GAR project was also fundamental for us in the development of the methodology for the construction of the 1961-1990 climatologies, which is presented in the following sections.

Figure 1 gives an overview of the stations used to describe the spatio-temporal behaviour of the temperature anomalies and those used to get 1961-1990 monthly climatologies, whereas the elevation distribution of the 767 stations used for the construction of the climatologies is shown in Fig. 2. Figures 1 and 2 give evidence that, even though some areas could benefit from a higher station density (e.g. Lombardy and Friuli), the data do not show major deficits neither in terms of spatial homogeneity nor in terms of vertical distribution.

\section{Estimating local secular anomaly records}

The estimation of the local secular anomaly record corresponding to any point $(x, y)$ of the area of interest is performed using the same method presented in Brunetti et 


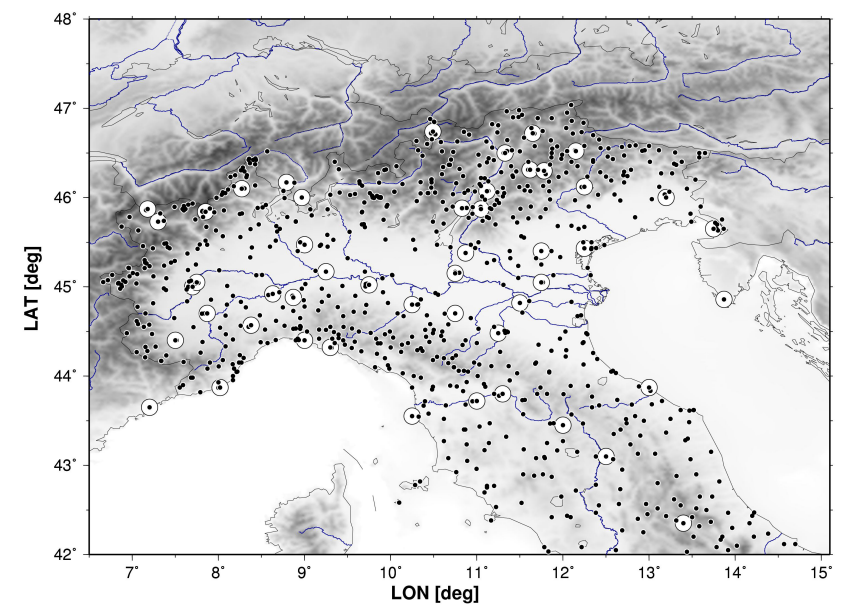

Figure 1. Large dots: stations used to describe the spatio-temporal behaviour of the temperature anomalies; small dots: stations used to get the spatial patterns of the 1961-1990 normal values.

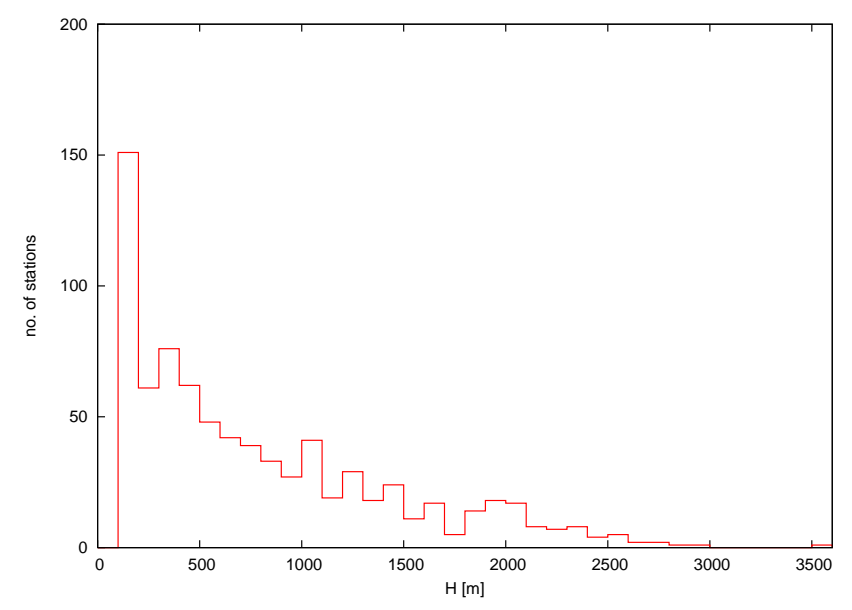

Figure 2. Vertical distribution of the stations used to get the spatial patterns of the 1961-1990 normal values.

al. (2006) for the gridding of the Italian secular temperature series: this method consists of averaging the data of the neighbouring stations by means of a Gaussian weighting function with the following form:

$w_{i}(x, y)=e^{-\frac{d_{i}^{2}(x, y)}{c}}$

with

$c=-\frac{\bar{d}^{2}}{\ln (0.5)}$

where $i$ runs along the stations and $d_{i}(x, y)$ is the distance between station $i$ and the point $(x, y)$ for which the local record is being estimated. With this choice of parameter $c$, we get weights of 0.5 for station distances equal to $\bar{d}$ from the point $(x, y)$, where $\bar{d}$ is defined as the mean value of the distances among each station of our database and its closest neighbor. The record for point $(x, y)$ is estimated under one of the following conditions: i) a minimum of two stations at a distance lower than $\bar{d}$, or ii) a minimum of one station at a distance lower than $\bar{d} / 2$. The computation is then performed by considering all stations within a distance of $2 \bar{d}$. The conditions for the calculation of the local secular anomaly record are always fulfilled after 1865 , whereas in the years previous to that date the calculation is possible only for a fraction of the points (for details, see Brunetti et al., 2006).

The ability to estimate local anomaly secular records was useful also to adjust the normals of the stations with missing data (or without data) in the 1961-1990 period. The adjustments were obtained by adding to each un-adjusted monthly temperature normal the difference among the averages of the corresponding anomaly record over a) the 1961-1990 period, and b) the period which was used to calculate the normal. As the first average is always null (the anomaly records have no missing data and they are expressed in terms of differences from the 1961-1990 averages), the procedure simply consists of subtracting from the un-adjusted normal value the second average. The local anomaly records are particularly suitable for this adjustment procedure because the database which was used to calculate them was subjected to a very accurate quality check and homogenisation procedure (Brunetti et al., 2006). So the time component derived from these data should be scarcely affected by station errors and inhomogeneities.

\section{1961-1990 high-resolution temperature climatolo- gies and super-imposition of the climatologies and the anomaly records}

\subsection{The geographical model}

1961-1990 high-resolution monthly temperature climatologies for Northern and Central Italy were obtained by means of a geographical model which incorporates the dependence of temperature on a number of geographical and morphological variables. This model was constructed by analysing the database shown in Fig. 1 by means of a step-wise linear regression method. This methodology permitted the effect of each variable on temperature to be detected, from the leading variable to the less important ones.

\subsection{The effect of the leading geographical variables}

The first variable we considered was elevation. To reduce the error, coast stations were not considered in the calculation of the regression coefficients. As expected, the highest (in absolute value) vertical lapse rates were found in summer, whereas the lowest ones were found in winter. Following this first regression, we subjected the residuals (i.e. the differences between the actual temperature normals and the estimated ones) to a new linear regression versus latitude; after 


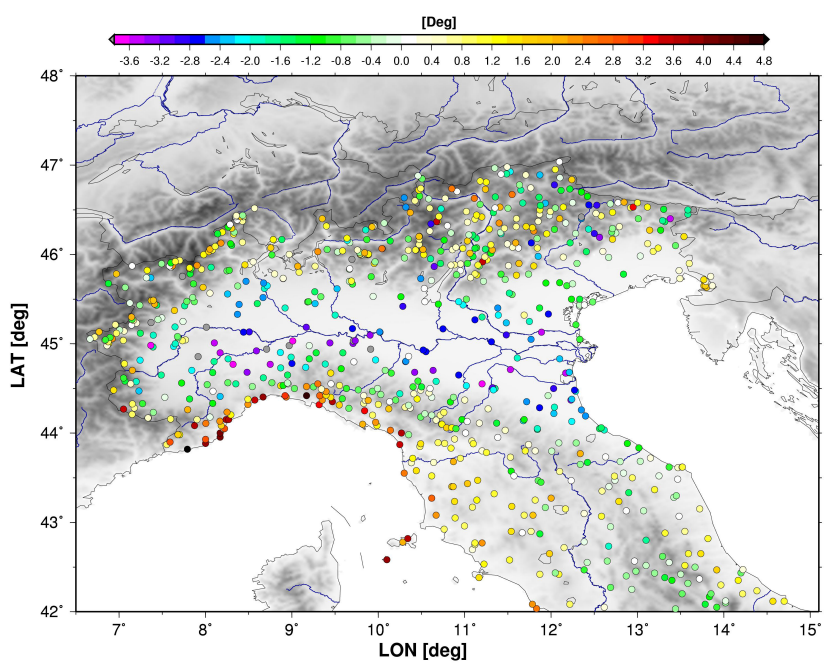

Figure 3. January residuals after considering elevation, latitude and longitude.

that we considered the new residuals and regressed them versus longitude. Once the temperature dependences on elevation, latitude and longitude were obtained on the basis of the station data, it was assumed that the same dependences could be extended to the whole study area. This extension was performed using the GTOPO30 30-arc-second-resolution digital elevation model (USGS, 1996).

\subsection{Further improvements}

The spatial distributions of the residuals obtained after considering the three leading geographical variables were further studied to identify more significant relations between temperature and geographical and morphological variables. An example of such spatial distributions is shown in Fig. 3. The figure concerns January: it gives evidence of a number of interesting features, the most prominent being the strong negative residuals in the Po Plain and the strong positive residuals along the Ligurian sea coast. Another method which allowed interesting information on the link between temperature and geographical or morphological variables to be captured consisted of comparing the average residuals of subsets of stations with similar characteristics, as, for example, the summit stations. Once a specific effect was identified, we tried to model it by linear regressions with geographical or morphological variables. If no significant results were found, the effect was modelled by simply attributing to all interested grid points the average residual over the stations affected by it.

This procedure, based on the analysis of the station residuals, was set up and developed in the frame of the ECSN HRT-GAR project. A more detailed discussion of the criteria for deciding whether to include or not a specific effect is given in Hiebl et al. (2009).
The first morphological variable taken into account was the summit location. Especially in winter, summit locations are expected to be warmer than what modelled by the leading geographical variables, as they receive the highest amount of direct solar radiation and they are scarcely affected by the cooling effect due to negative radiative balance at the surface, which produces thermal inversions during the night. To investigate this effect, we defined a subset of 64 stations belonging to grid cells with elevation higher than the one of the eight surrounding cells and located above a $400 \mathrm{~m}$ threshold: we considered the average of the monthly residuals of this subset and assigned it to all summit locations in our area of interest.

The second morphological effect taken into account was the geographical slope exposure (hereinafter "facet"). The station facets were estimated by associating the grid cell facets, as provided by the digital elevation model, to all pertaining stations. These grid cell facets were simply calculated as the direction of the gradient of the function $z=z(x, y)$, where $\mathrm{z}$ is the elevation and $x$ and $y$ are the coordinates defined according to eastward and northward axes respectively. To investigate the facet effect, we analysed the monthly residuals of a subset of 217 stations belonging to grid cells whose slope is higher than $50 \mathrm{~m} / \mathrm{km}$ and that are not summit locations. The analysis did not produce remarkable results for north-facing cells; on the contrary, south-facing locations showed positive residuals in all months, with values peaking in summer. To capture the overall facet effect, we introduced the following model:

$R_{\text {facet }}=\alpha \cdot \sin ($ facet $)$

where facet, here varying in the $[0, \pi]$ range, represents the direction of the gradient of $z(x, y)$, expressed by using counter-clockwise rotation and angles originating at the eastward direction. $\alpha$ is a monthly-dependent coefficient that was identified by considering the residuals of the most southfacing stations in our database. The facet effect was assigned to all non-summit grid cells with slope higher than $50 \mathrm{~m} / \mathrm{km}$ and with exposure ranging from $\mathrm{W}$ to $\mathrm{E}$ (using counterclockwise rotation).

The next effect taken into account was the influence of the sea. Four separate zones were considered on the basis of the station residuals: Ligurian Sea (French Riviera and Liguria), Tyrrhenian Sea (Tuscany and northern Latium), NorthEastern Adriatic Sea (Friuli and Istria) and South-Western Adriatic Sea (Veneto, Emilia-Romagna and Marche). This partition was also supported by the geographical characteristics of Northern and Central Italy: the Ligurian and Tyrrhenian Seas are both on the western side of the Italian Peninsula, being respectively on the south and west of the mainland. The Adriatic Sea is on the eastern side of Italy and is more exposed to cold air masses coming from the Balkans: its northern part is located mostly on the south of the mainland, whereas the part from Veneto to Marche is mostly to the east of the mainland. 
(a)

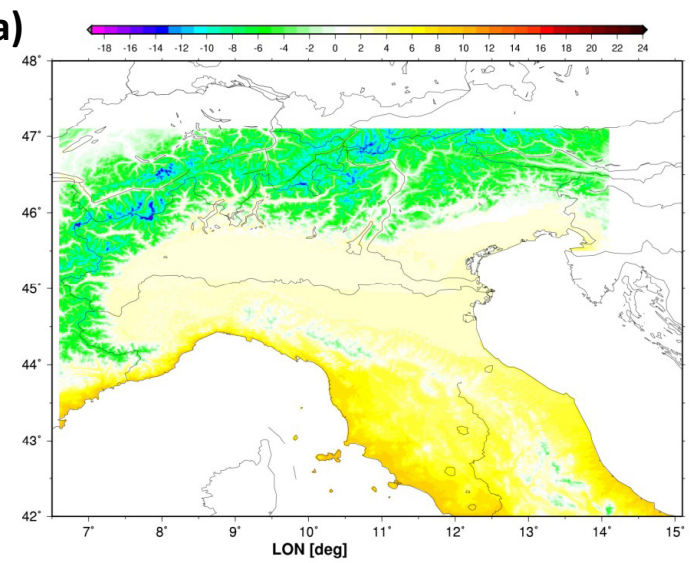

(c)

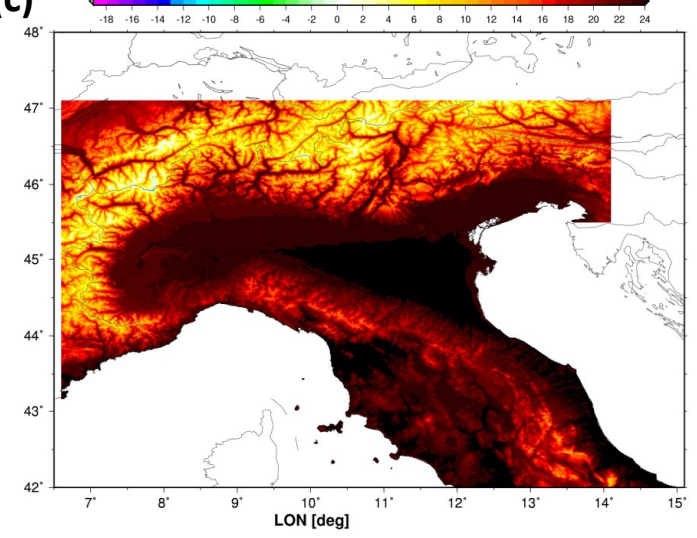

(b)

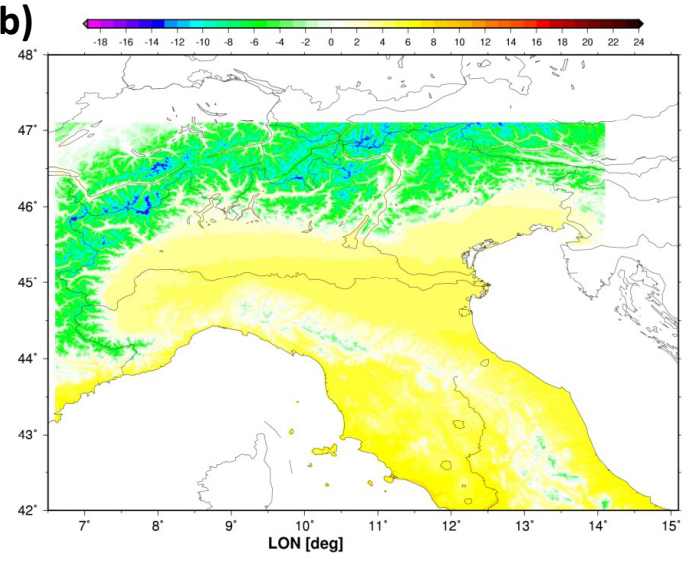

(d)

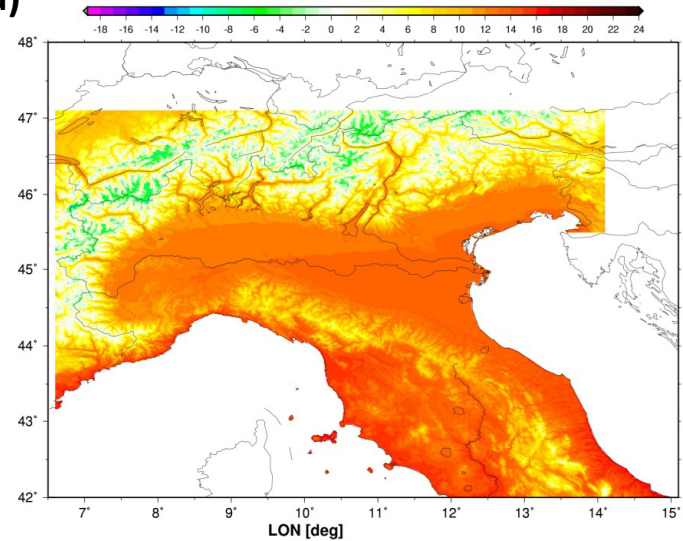

Figure 4. (A) January, (C) July and (D) annual 1961-1990 Northern and Central Italy temperature climatologies. The figure also shows (B) the January temperature climatology obtained by taking into account only elevation, latitude and longitude.

To investigate the sea effect, we considered each zone separately; we then selected a subset of stations located not farther than $50 \mathrm{~km}$ from the corresponding sea and we performed a linear regression between the station residuals and the distances from the coast. The effect was assigned to all grid cells within a distance of $50 \mathrm{~km}$ from the Tyrrhenian Sea and the Northern Adriatic Sea, of $40 \mathrm{~km}$ from the Southern Adriatic Sea and of $25 \mathrm{~km}$ from the Ligurian Sea. These distances were defined on the basis of the station residuals.

The same approach was adopted for 3 sub-Alpine lakes (Lake Maggiore, Como and Garda). In this case, however, the effect was only studied and assigned to the areas located within $10 \mathrm{~km}$ from the lakes.

The following effect taken into account was the "Po-Plain" effect. The Po Plain shows a remarkable continentality, which causes rather low temperatures in winter, especially from December to February. To study this effect we analysed the residuals of a subset of 145 stations selected considering i) the geographical limits of the Po Plain, ii) an elevation not higher than a threshold ranging from 250 to
$500 \mathrm{~m}$, according to the considered area, iii) a slope threshold of $100 \mathrm{~m} / \mathrm{km}$. The analyses highlighted a significant dependence of the residuals on elevation, as well as on the season that was modelled and assigned to all Po Plain grid cells.

In the end, we plotted the residuals obtained after the Po Plain effect evaluation and we found that in some areas the residuals were still higher than $1.5^{\circ} \mathrm{C}$ and in some other areas they were still lower than $-1.5^{\circ} \mathrm{C}$. Thus, we introduced some more corrections in the geographical model to take into account these local effects. In particular we found some areas with remarkable negative residuals in winter (the SouthWestern Piedmont hills and the Adige valley), other ones with remarkable negative residuals in summer (Ossola), others with remarkable positive residuals in summer (Adige valley), and some with negative residuals all year round (Carnia). To take into account these effects, we assigned corrections identified according to the average station residuals to the grid cells corresponding to the listed areas. 
Table 1. Accuracy of the climatologies quantified by mean error (ME), mean absolute error (MAE) and root mean squared error (RMSE). The table also shows the monthly errors of 2 of the 767 station normals: Rovigo and Cortina.

\begin{tabular}{lrrrrrrrrrrrrr}
\hline & Jan & Feb & Mar & Apr & May & Jun & Jul & Aug & Sep & Oct & Nov & Dec & Average \\
\hline ME & 0.05 & 0.04 & 0.02 & 0.04 & -0.01 & -0.01 & -0.01 & 0.00 & 0.02 & 0.04 & 0.05 & 0.04 & 0.02 \\
MAE & 0.86 & 0.74 & 0.66 & 0.63 & 0.64 & 0.67 & 0.70 & 0.73 & 0.66 & 0.67 & 0.74 & 0.86 & 0.71 \\
RMSE & 1.09 & 0.94 & 0.83 & 0.78 & 0.79 & 0.84 & 0.89 & 0.91 & 0.83 & 0.84 & 0.93 & 1.10 & 0.90 \\
Error Rovigo & 0.16 & -0.04 & -0.23 & -0.12 & -0.03 & 0.08 & -0.22 & -0.59 & -0.79 & -0.61 & -0.27 & -0.24 & -0.24 \\
Error Cortina & -1.18 & -0.96 & -0.75 & -0.37 & -0.25 & -0.34 & -0.38 & -0.61 & -0.71 & -0.81 & -0.71 & -0.98 & -0.67 \\
\hline
\end{tabular}

\subsection{The monthly climatologies and their accuracy}

The January and July monthly temperature climatologies obtained by taking into account all the described variables are shown in Figs. 4a and c, whereas Fig. 4d shows the annual temperature climatology. To display an example of the effect of the non-leading geographical variables, in Fig. 4b we also show the January climatology estimated only on the basis of elevation, latitude and longitude.

For each month of the year, the overall accuracy of the climatologies was evaluated by comparing the 767 station normals of our database with the corresponding model estimations. The accuracy of the climatologies was quantified by the following statistical parameters: mean error (ME), mean absolute error (MAE) and root mean squared error (RMSE). The results are shown in Table 1. They are in good agreement with the ones obtained for the Greater Alpine Region 19611990 climatologies (Auer et al., 2008; Hiebl et al., 2009) and they are comparable with the errors of other well known climatologies, like the ones produced by Daly et al. (2008) for the conterminous United States. The Daly et al. (2008) climatologies were constructed by different procedures, but on a database with a comparable spatial resolution. The errors shown in Table 1 are naturally not only due to the model; an indefinable, but potentially large, fraction of the difference between the estimated and the observed normals is in fact likely to be due to the fact that the stations could be not completely representative of the corresponding grid cells, as well as to errors in the station data themselves.

Table 1 also shows the monthly errors of 2 of the 767 station normals: Rovigo and Cortina. These stations will be used in Sect. 4.5 to show examples of comparisons between observed and reconstructed absolute value temperature records. The errors of Rovigo are lower than the corresponding MAEs, with the only exception of September, whereas the errors of Cortina are lower than the corresponding MAEs in summer and higher in autumn and winter.

Another method for the evaluation of the climatologies consisted of plotting the spatial distributions of the final residuals. These plots are shown in Fig. 5 for January and July. The comparison of these plots with the corresponding plots which were obtained after considering only elevation, latitude and longitude gives evidence of the importance of

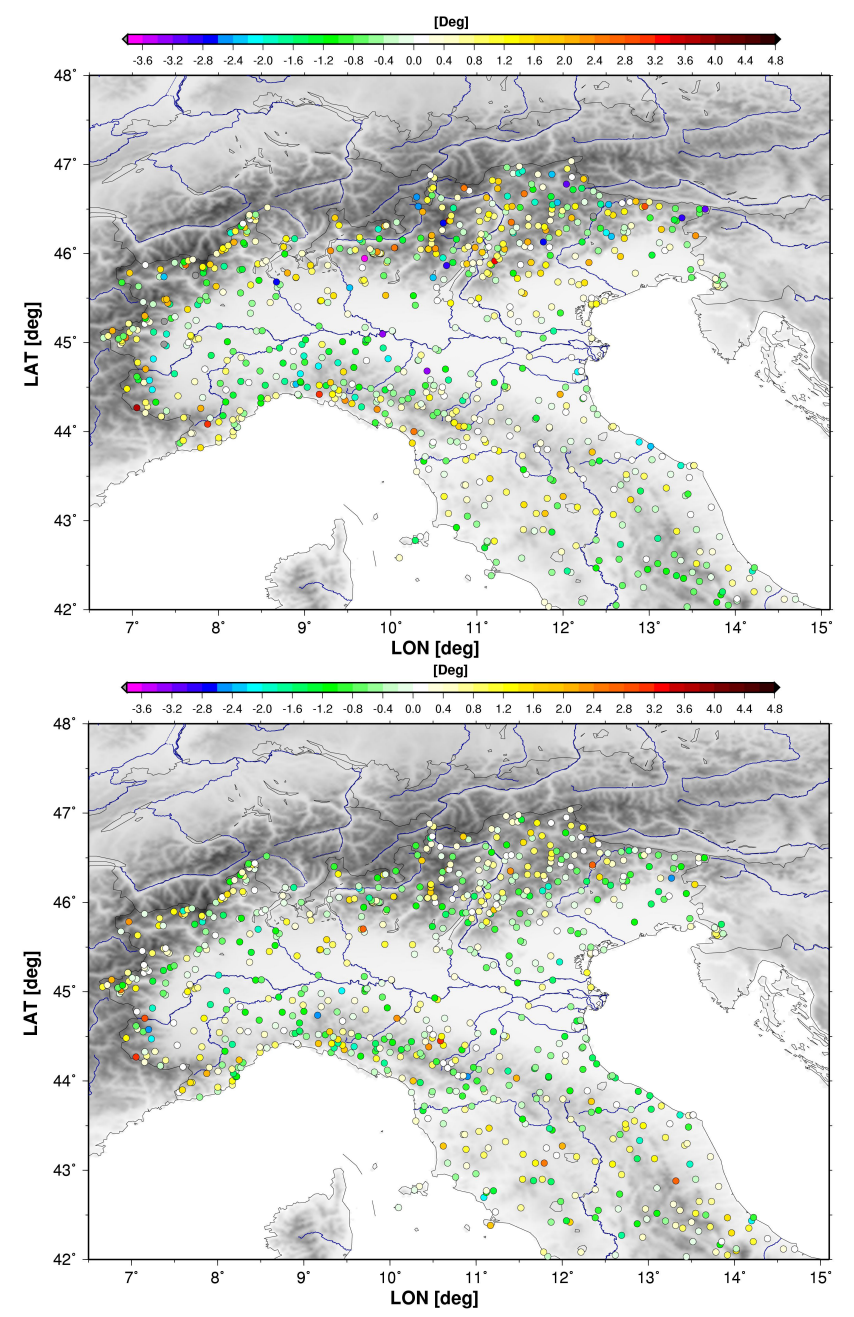

Figure 5. (A) January and (B) July final station residuals.

the improvements obtained by taking into account all the effects discussed in Sect. 4.3. These improvements are particularly evident in winter (compare Figs. 3 and 5a), whereas in summer the local improvements are less important as a very high fraction of the variance of the temperature normals is explained by elevation. 

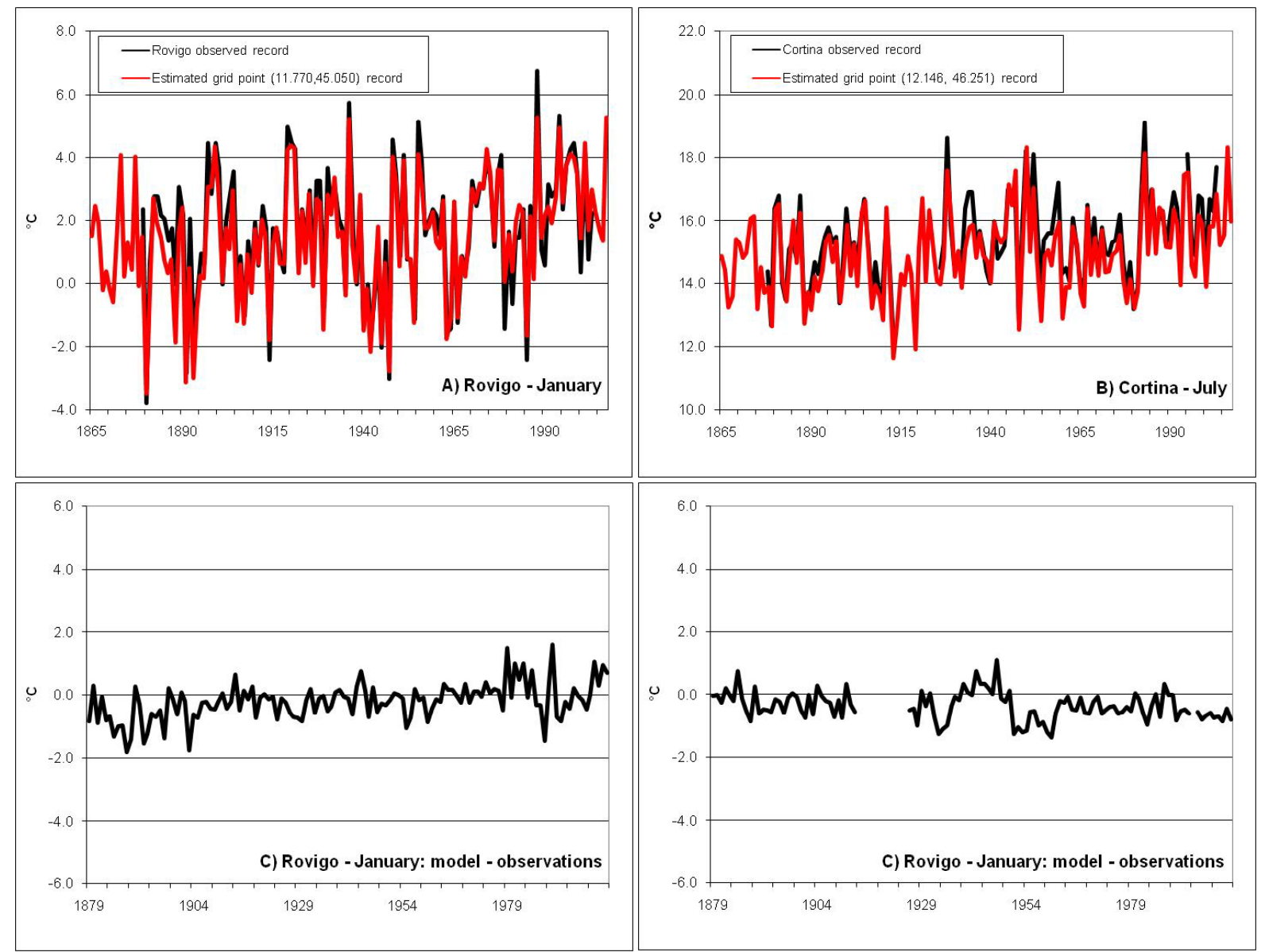

Figure 6. Comparison between original and estimated records. (A) Rovigo vs. grid point (11.771, 45.054), January, (B) Cortina vs. grid point (12.146, 46.521), July. (C and D) Differences between reconstructed and observed records.

\subsection{Superimposition of the climatologies and the temper- ature anomaly records}

The ability to estimate local secular anomaly records for any point of Northern and Central Italy and the availability of high resolution climatologies enable us to estimate secular absolute value temperature records for any point of this area. These estimated local secular records are simply obtained by adding the corresponding 1961-1990 monthly temperature normals to the local estimated monthly secular anomaly records.

To check the procedure, we deleted some secular records from our database, estimated the records of the corresponding grid points and compared the estimated records with the original ones. Two examples are shown in Fig. 6. The first (A) concerns January at Rovigo (longitude: $11.771 \mathrm{E}$, latitude: $45.054 \mathrm{~N}$, elevation: $5 \mathrm{~m}$ ), the second (B) July at Cortina d'Ampezzo (longitude: $12.146 \mathrm{E}$, latitude: $46.521 \mathrm{~N}$, elevation: $1275 \mathrm{~m}$ ). The figure also shows the differences between the observed and the estimated records $(\mathrm{C}$ and $\mathrm{D}$ for Rovigo and Cortina, respectively): the comparison of these difference records with the observed records (A and B) highlights that the reconstructed records explain a high fraction of the variability of the data (the common variances of the original and the reconstructed records are $91 \%$ for Rovigo, January and $88 \%$ for Cortina, July). Beside this result, the difference records also give evidence of some minor problems, which may concern either the observed or the reconstructed records (or both of them). In fact, on one hand their averages are not null as a consequence of the errors of the reconstructed 1961-1990 normals (see Table 1) and on the other they give evidence of periods which have values that seem to be systematically different from the long-term averages. This behaviour is due to the fact that the anomaly records may still contain small inhomogeneities. These inhomogeneities are present in all meteorological records, even after being subjected to an accurate homogenisation procedure. Homogenisation, in fact, strongly reduces station inhomogeneities, but it does not completely eliminate them (see Brunetti et al. (2006) for a more detailed discussion of such an issue). Comparisons as the ones shown in Fig. 6 generally highlighted a good agreement between the estimated and the 
original records and also showed that the estimated records were very useful to fill missing data in the original series.

The methodology for estimating local secular absolute value temperature records has already proved useful for Northern and Central Italy in the frame of several climate change impact-related projects, such as CARIPANDA (Lombardy Regional Project coordinated by Parco dell'Adamello, http://www.parcoadamello.it/progetti/default.htm) and Kyoto Lombardia (Lombardy Regional Project coordinated by Fondazione Lombardia per l'Ambiente, http://www.flanet. org/ricerca/kyoto.asp). The estimated records were also used in order to downscale to the local level future records produced by the General Circulation Models (GCMs); thus, the estimated local records not only permit the best assessment of local past temperature variability and change, but they also allow the GCM information to be tailored to the need to assess local impacts of future climate change.

\section{Conclusions}

A methodology was developed for estimating secular absolute value temperature records for any point of Northern and Central Italy. It is based on the superimposition of two fields: the 1961-1990 normals and the departures from them. These two fields were obtained in a completely independent way from each other and are based on completely different databases. The spatio-temporal structure of the temperature anomalies was simply obtained by considering weighted averages of the Italian secular records (Brunetti et al., 2006), whereas the construction of the spatial patterns of the 19611990 temperature normals required the collection of a huge amount of new data and the construction of a geographical model which incorporates the dependence of temperature on a number of geographical and morphological variables. A large amount of the studies for the construction of such spatial patterns have been performed within the ECSN HRTGAR project. Within this project the Italian climatologies have also been compared with corresponding Greater Alpine Region (GAR) climatologies (Auer et al., 2008; Hiebl et al., 2009) which were obtained with a similar approach. The comparison between the northern and central Italy and the GAR climatologies shows a similar level of accuracy: this level of accuracy is also comparable to the one found by Daly et al. (2008).

The ability to estimate local secular absolute value temperature records is particularly useful in the frame of climate change impact-related projects. The estimated local records, not only permit the best assessment of local past temperature variability and change, but they also allow the GCM information to be tailored, by downscaling procedures, to the need to assess local impacts of future climate change.

Naturally, the records estimated by the discussed methodology must be considered with a clear awareness of the actual spatial resolution achievable with the available data. Thus, they can not highlight very local effects in time variability as the actual spatial resolution of the secular temperature anomaly records is of about 1 station per $4000 \mathrm{~km}^{2}$. In the same way, they can not take into account effects which are not included in the geographical model, even though they may be relevant for some areas (e.g. land cover and in particular urban heat islands). At present these effects are under investigation by our research group and further results will be discussed in upcoming papers dealing with these topics. In the near future we will also proceed to extend the climatologies from Northern and Central Italy to the whole national territory and consider also minimum and maximum temperatures.

Acknowledgements. We would like to thank all data providers who enabled the databases presented and discussed in the paper to be set up. Among them, in particular, we thank the Ufficio Centrale di Ecologia Agraria (UCEA) and the Servizio Idrografico as far as the secular records are concerned; and APAT, Italian Air Force, regional environmental agencies (ARPAs of Liguria, Piemonte, Lombardia and Emilia Romagna), Meteo Trentino, Società Meteorologica Italiana and ENEL for the time series for the climatologies. We would also like to acknowledge the INTERREG Project FORALPS, the Lombardia Project Kyoto, the Parco Naturale dell'Adamello - CARIPLO Project CARIPANDA, the US-ITALY bilateral Agreement on Cooperation in Climate Change Research and Technology (Italian Ministry for the Environment), the project "Sviluppo e verifica di tecniche di downscaling e calibrazione di modelli idrologici, sulla base di una griglia termopluviometrica ad altissima risoluzione $(1 \mathrm{~km} \times 1 \mathrm{~km})$ per gli ultimi 150 anni, per la valutazione dell'impatto dei cambiamenti climatici sulla risorsa idrica" in the frame of the framework programme agreement between the Dipartimento Terra e Ambiente of the CNR and the Centro Euro-Mediterraneo per i Cambiamenti Climatici, and the Milan University $\mathrm{PhD}$ research grant which supported the Project HRT NI - High Resolution Temperature Climatology Northern Italy, which was developed parallel to ECSN/HRT GAR. In this context, valuable discussions with colleagues in the project provided fundamental insights for methodology developments and improvements. We would also like to thank all researchers and collaborators who, over the years, have helped in collecting, quality checking and homogenizing the databases: namely Fabio Monti, Rossella Pastorelli, Adriana Fassina, Claudia Mazzola, Nicola Cortesi, Diana Cricchio.

Edited by: M. Dolinar

Reviewed by: two anonymous referees

\section{References}

Auer, I., Böhm, R., Hiebl, J., Schöner, W., Spinoni, J., Lentini, G., Maugeri, M., Brunetti, M., Nanni, T., Perèec Tadiæ, M., and Bihari, Z.: Final Report of the ECSN Project "HRT/GAR - High Resolution Temperature Climatology in Complex Terrain - demonstrated in the test area Greater Alpine Region Gar. Final Report and Annexes 1-4, http://www.zamg.ac.at/forschung/ klimatologie/klimamodellierung/ecsn_hrt-gar/, 2008. 
Brunetti, M., Maugeri, M., Monti, F., and Nanni T.: Temperature and precipitation variability in Italy in the last two centuries from homogenised instrumental time series, Int. J. Climatol., 26, 345$381,2006$.

Daly, C., Halbleib, M., Smith, J. I., Gibson, W. P., Doggett, M. K., Taylor, G. H., Curtis, J., and Pasteris, P. A.: Physiographicallysensitive mapping of temperature and precipitation across the conterminous United States, Int. J. Climatol., 28, 2031-2064, doi:10.1002/joc.1688, 2008.

Hiebl, J., Auer, I., Böhm, R., Schöner, W., Maugeri, M., Lentini, G., Spinoni, J., Brunetti, M., Nanni, T., Percec Tadiæ, M., Bihari, Z., Dolinar, M., and Müller-Westermeier, G.: A highresolution 1961-1990 monthly temperature climatology for the greater Alpine region, Meteorol. Z., submitted, 2009.

Mitchell, T. D. and Jones, P. D.: An improved method of constructing a database of monthly climate observations and associated high-resolution grids, Int. J. Climatol., 25, 693-712, 2005.
New, M., Hulme, M., and Jones, P. D.: Representing twentieth century space-time variability. Part 2: development of 1901-96 monthly grids of surface climate, J. Climate, 13, 2217-2238, 2000.

Petrarca, S., Spinelli, F., Cogliani, E., and Mancini, M.: Profilo Climatico dell'Italia, ENEA, http://clisun.casaccia.enea.it/Pagine/ Profilo.htm (last access: 28 April 2009), 1999 (in Italian).

Servizio Idrografico: Distribuzione della temperatura dell'aria in Italia nel trentennio 1926-1955. Pubblicazione N. 21 del Servizio Idrografico del Ministero dei Lavori Pubblici, 1966 (in Italian).

USGS (United States Geological Survey): GTOPO30 Documentation, http://edc.usgs.gov/products/elevation/gtopo30/README. html (last access: 28 April 2009), 1996. 